\title{
The Semi-Arid Integrated Model (SIM), a Regional Integrated Model Assessing Water Availability, Vulnerability of Ecosystems and Society in NE-Brazil
}

\author{
M. S. Krol, A. Jaeger, A. Bronstert and J. Krywkow
}

Potsdam Institute for Climate Impact Research (PIK), P.O. Box 601203, 14412 Postdam, Germany

Received 15 May 2000; accepted 21 September 2000

\begin{abstract}
Northeastern Brazil, an example of vulnerable semi-arid regions on the earth, is characterised by water scarcity and vulnerability of natural resources, pronounced climatic variability and social stress situations. Integrated studies involving hydrology, ecology, meteorology, climatology, pedology, agronomy, and social and economic sciences are required not only for analysing consequences of the adverse natural conditions but also to assess possible strategies to make semi-arid regions less vulnerable to the present and changing climate.

Integrated modelling of the relationships between water availability, quality of life and migration, including aspects of global change processes, in the Semi-arid Integrated Model (SIM) serves to understand the dynamics of the system. An overview of the concept, structure and application results of the integrated model are given.

A sensitivity study on climate change illustrates potentially significant adverse effects on the region. Moreover, it shows that a regional integrated model is a suitable tool for complex and interdisciplinary studies. The present version of SIM still is in a development phase, especially in its representation of socio-economic processes. (C) 2001 Elsevier Science Ltd. All rights reserved
\end{abstract}

\section{Introduction}

In North-eastern Brazil, the limited availability of water resources poses a serious limitation to society. This limited availability results from a moderate rainfall amount, which is generally unreliable and unfavourably distributed in time, and a high evaporation rate. As a result, drinking water supply and agriculture are vulnerable, especially when they cannot rely on water supply from storage facilities or ground water, as is the case in vast rural areas. In the irregularly recurring droughts, water shortage is a general problem in the region, with migration as one of the societal

Correspondence to: M. S. Krol (krol@pik-potsdam.de) responses. Possible policies to alleviate the vulnerability of the region relate to water management, land use, public participation, amongst others.

The assessment of the problem and of approaches to relieve it requires an integrated understanding of how climate, water resources, agriculture and society influence each other. The central challenge in integrated assessment is to get a comprehensive picture involving many scientific disciplines while guaranteeing mutual consistency. The most explicit way to attack this scientific question is integrated modelling.

\section{Integrated modelling}

Integrated modelling starts with a systems analysis of the problem studied. Here, the WAVES project (Water Availability, Vulnerability of Ecosystems and Society) focuses on the assessment of relationships between water availability and quality of life and migration in rural semiarid North-eastern Brazil at the meso-/macro-scale in the context of global change, especially climate change. A topdown analysis of the problem identifies which are the basic variables, processes, and external forcing that should be accounted for in the integrated model (Fig 1).

In this analysis, the focus is explicitly on internal features of the most relevant dynamic behaviour rather than on what is best understood, as for instance the influence of water scarcity on water consumption. The specific challenge is to find a good compromise between the clarity in the representation and the comprehensiveness regarding the main dynamical processes (find $20 \%$ of processes explaining $80 \%$ of dynamics). Special attention should be paid to cross linkages and feedback processes, which may be of minor importance in the present functioning of the system, but could importantly influence long-term dynamics, as for instance the effects of migration on the agricultural sector.

A specifically interesting feature of the dynamics is the ability of the system to dampen (or enhance) the variability resulting from the variable climate forcing. Here e.g. water infrastructure and water policy can cause a reduced variability in availability of water resources, but in 


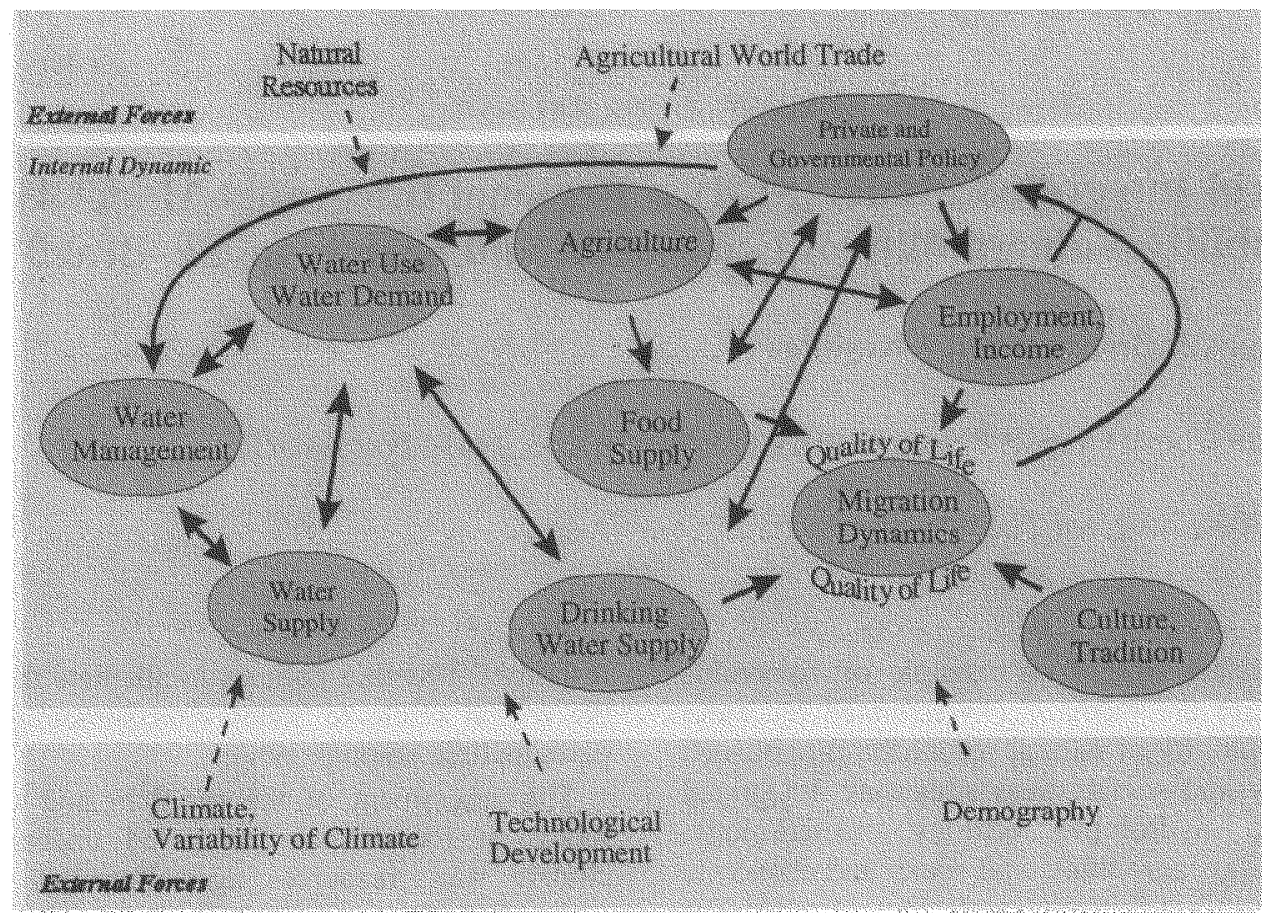

Figure 1. Systems analysis of relations between water availability and impacts on socio-economy under global change influence.

agriculture and social dynamics the exceeding of threshold values of water availability or income may suddenly trigger strong impacts on crop yield or migration, implying an increase in variability along the causal chain. The usage of adapted crops and rural policy or drought emergency policy may dampen again.

The context of global change forces the analysis to consider long-term behaviour of the system. A reásonable dynamic understanding is preferred over an excellent static understanding, and processes influencing long-term changes are more in focus than processes just explaining heterogeneity at the micro-scale. Clearly, only (aggregated) process-based models can simulate both the effects of individual influences of global change and policy interventions. In this sense, integrated models generally show a mix of deductive (top-down) and inductive (bottomup) approaches. Here, the poor availability of data on many themes at the targeted scale also plays a role.

The goal of the present study is to improve the integrated dynamic understanding of the causal chain climate - water availability - agriculture - society. In this analysis, geographically explicit integrated modelling is chosen as the most explicit way to approach consistency considerations and regional validity. The Semi-arid Integrated Model (SIM) was constructed for this regional integrated modelling at the meso-/macro-scale, and is extending the commonly found integrated modelling further into human dimensions. SIM is also explicitly meant as a tool to support policy assessment. Present applications of the model focus on historic simulations for validation and studies of the sensitivity to climate variability/change. Future applications will consider integrated scenarios of global and regional change with variations in regional policy interventions. Those scenarios will be analysed as possible pathways of future development, considering aspects of sustainability.
The research area of integrated modelling is developing rapidly in the context of climate change studies. Originating from natural science models, extended to include climate change impacts, like IMAGE 2 (Alcamo et al., 1994), or from macro-economic models, extended with impact cost estimates (like GCAM, Edmonds et al., 1994), the modelling moves into an arca where the integration approach is more central (like ICLIPS, Toth et al., 1997 or TARGETS, Rotmans and de Vries, 1997).

Regional climate impact assessments also tend to include more integrative approaches, extending from agricultural impacts (MINK study, Rosenberg et al., 1993) to representation of interests of various socio-economic sectors (MBIS study, Cohen, 1997). Earlier regional studies on North-eastern Brazil (UNEP study of climate variability and agriculture in the semi-arid tropics, Magalhães et al., 1988) were broad and rich in information but did not arrive at an integrative concept as adopted in WAVES (Bronstert et al., 2000).

\section{Model description}

The Semi-arid Integrated Model (SIM) is a concrete implementation of the result of the systems analysis (Fig 1). The model is built up in a modular way, roughly representing the disciplinary contributions. The modules are mainly based on contributions from the various research partners in the WAVES program. The main components of SIM are:

Climate: Climate scenarios or a historic reconstruction are input to SIM, and results from long-term daily observations combined with climate trends from Global Circulation Models. 
a)

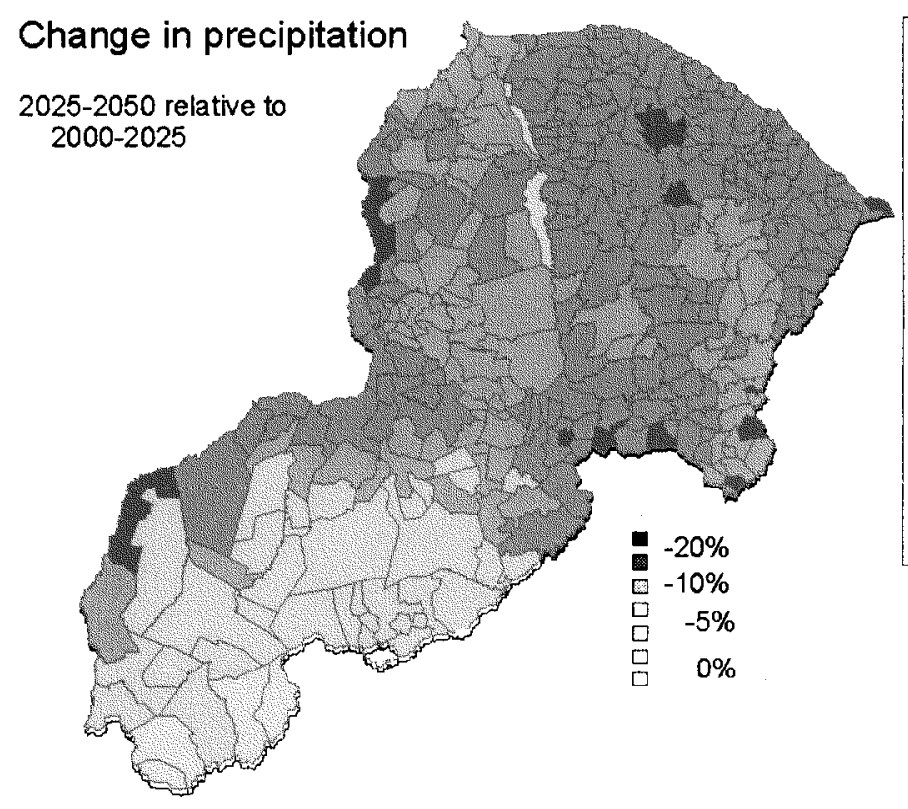

b)

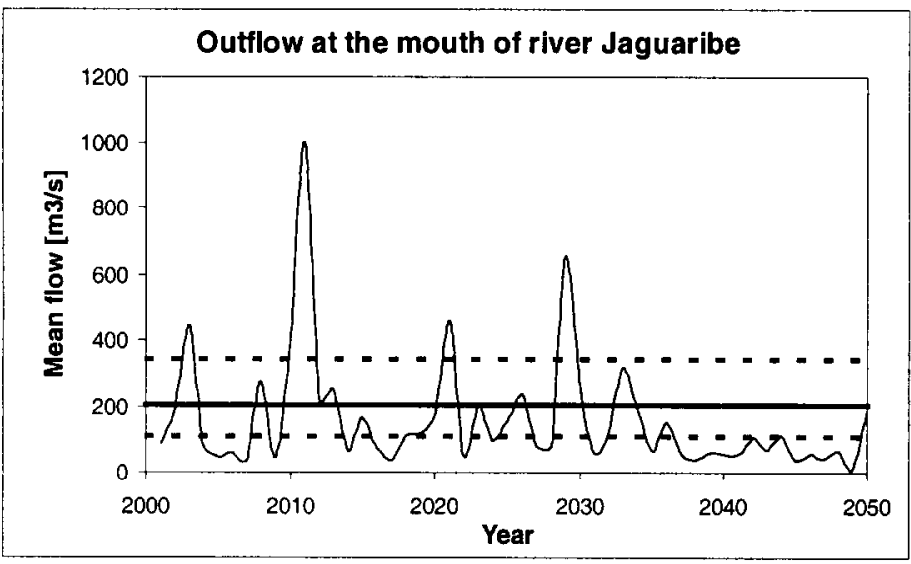

c)

\section{Relative fulfilment of water demand dry season 2024}

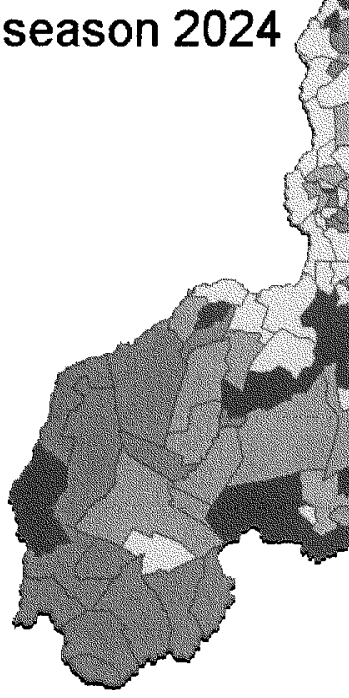

d)

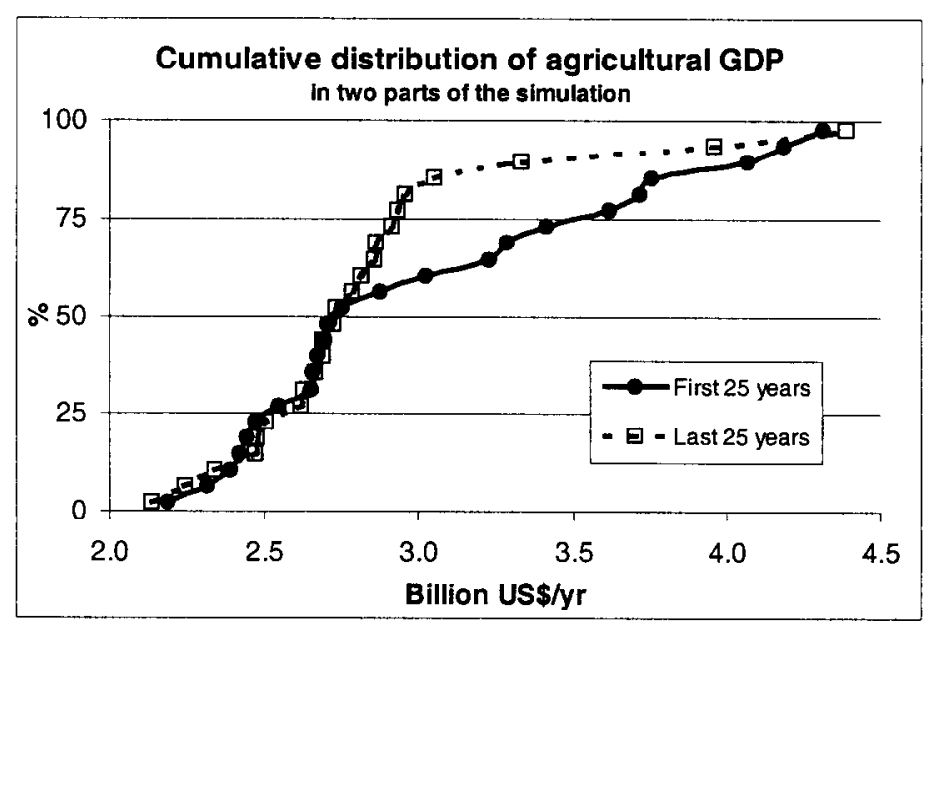

Figure 2. Example results of SIM for a 'business-as-usual' climate change scenario

a) regional interpretations of specific GCM results show significant reductions in precipitation in Cearâ and Piaui over the next 50 years,

b) the mean annual outflow of the river Jaguaribe shows a downward trend, for comparison the 25, 50 and 75 percentiles of historic simulated outflow are shown,

c) the restricted fulfilment of water demand in the dry season of 2024, shows significant reductions in water use due to supply constraints, an illustrative useful model-derived output indicators;

d) agricultural GDP shows a marked difference between the first and last $25 \%$ of the simulation, where the probability of the better economic returns diminishes. 

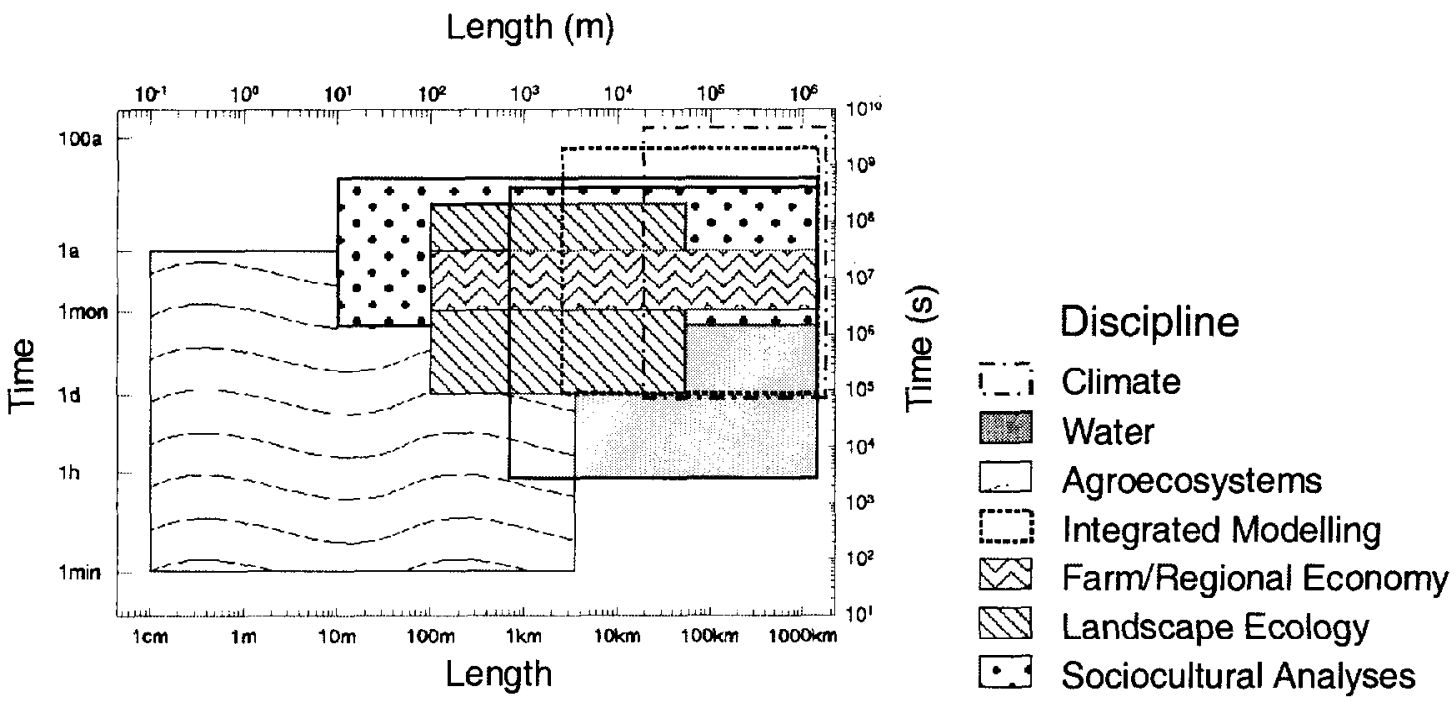

Figure 3. Typical spatial and temporal scales of research for the various disciplines in WAVES.

Water availability: A large scale water balance model describes run-off, storage in water reservoirs and soil moisture based on a hydrotope-approach (typical size $10-50 \mathrm{~km}^{2}$ ), accounting for vertical and lateral processes depending on topography, soil and vegetation cover, with an explicit representation of the main water reservoirs. A water use model simulates water withdrawal, considering the various water use sectors and their specific intensity and efficiency, directly coupled to the agricultural and demographic models.

Agriculture: Crop yields are simulated using a FAO scheme for yield response to water stress, as used in CROPWAT, for the 14 regionally most important crops (including maize, bean, rice, cashew). Agro-economy is represented as optimising farm income by varying cropping and husbandry activities, under restrictions of available land, technical and financial opportunities, and feed and food requirements, and accounting for production costs and prices.

Socio-economy: Migration amongst municipalities and to external destinies is preliminarily modelled to occur when gradients in the quality of life exceed migration costs (fixed and distance-dependent). Here quality of life is a composite indicator, where mean municipal income per head is the dominant influence. Migration is accounted for in a demographic model resolving for age and gender.

The connection and completion of the disciplinary contributions to the full integrated model requires the consideration of consistency between disciplines, harmonisation of scales, and the filling of gaps, e.g. how water scarcity influences water consumption. Here, the systems analysis (Fig 1) proved useful as a concrete conceptual model design, steering the explicit definition of module interfaces.

\section{Climate change sensitivity and scaling issues}

Preliminary sensitivity calculations focused on the effects of climate changes according to a business-as-usual scenario of ECHAM 4 (Fig. 2). Results indicate that climate change may have serious effects on northeastern Brazil, with appreciable reductions in river flow and agricultural GDP, if no counteracting policies are put through. Possible policy responses like improved water infrastructure, changes in the agricultural sector were not studied in this sensitivity study but will be considered in forthcoming integrated scenario runs

The issue of scaling is of great importance in integrated modelling. The various contributing disciplines each have their specific spatial and temporal scales of research in modelling and fieldwork (Fig 3). The harmonisation of these scales and connection of parameterisation at different scales are a key part of integrated modelling. The overlap between the works at different scales allows up- or downscaling procedures to be developed. In SIM, all simulations are defined at the scale of municipalities (of typically $1000 \mathrm{~km} 2$ ) with a higher spatial resolution for the water balance and crop yield calculations. Temporal resolution ranges from one day (in hydrology) to one year (in socio-economy). The interfaces between modules are generally defined at the finest common spatial and temporal resolution.

\section{Conclusions}

It can be concluded that SIM already shows a successful integration of models over the complete causal chain climate - water availability - agriculture - socio-economic impacts. Still some modules are in their developing stages, but here SIM offers an effective integrated framework for model design and testing. 
Model application shows the large sensitivity of the region to possible climate change, where both water resources and agriculture show a significant negative impact under plausible precipitation reductions. Applications are still restricted to climate sensitivity studies but will amplify in the coming years.

The model has the potential to perform scenario analyses, including studies of regional impacts of global change, but also of the effectiveness of regional policies on water management and land use, as responses to climate variability and possible global change.

Acknowledgements. This research was supported by the German Bundesministerium für Bildung und Forschung (BMBF) under grant $01 \mathrm{LK} 9713 / 4$, and draws on research findings of partner institutes in the WAVES program, funded by BMBF and the Brazilian Conselho Nacional de Desenvolvimento Científico e Tecnológico (CNPq).

\section{References}

Alcamo, J., Kreileman, G.J.J., Krol, M.S. and Zuidema, G. (1994): Modeling the global society-biosphere-climate system: Part 1: Model description and testing, Water, Air, and Soil Pollution. 76, 135.

Bronstert, A., Jaeger A., Güntner A., Hauschild, M., Döll, P. and Krol, M. (2000). Integrated modelling of water availability and water use in the semi-arid Northeast of Brazil, Physics and Chemistry of the Earth (accepted for publication)
Cohen, S.J. (Ed.), 1997. MacKenzie Basin Impact Study (MBIS), Final Report, Atmospheric Environment Service, Environment Canada, Toronto.

Edmonds, J.A., Wise, M. and MacCracken, C. (1994). Advanced energy technologies and climate change: an analysis using the global change assessment model (GCAM). PNL-9798, UC-402. Richland, Washington: Pacific Northwest Laboratory.

Magalhães, A.R., Filho, F.C., Garagorry, F.L., Gasques, J.G., Molion, L.C.B., Neto, da S.A., Nobre, C.A., Port, E.R. and Rebouças, O.E. (1988): The effects of climatic variations on agriculture in Northeast Brazil. Part III in: M.L. Parry, T.R. Carter and N.T. Konijn (eds.): The Impact of Climatic Variations on Agriculture, Vol. 2: Assessments in Semi-Arid Regions. Kluwer Academic Publishers, 273-380.

Rosenberg N.J., Crosson, P.R., Frederick, K.D., Eastcrling W.E., McKenny, M.S., Bowes, M.D., Sedjo, R.A., Dramstadter, J., Katz, L.A. and Lemon, K.M. (1993). The MINK methodology: background and baseline. In: Towards an integrated impact assessment of climate change: the MINK study. Reprinted from Climatic Change 24: 1.2, 1993, ed. Rosenberg, N.J. Dordrecht, The Netherlands, Kluwer Academic Publishers.

Rotmans, J. and de Vries, H. J. M. (1997). Perspectives on Global Change: The TARGETS approäch. Cambridge University Press, Cambridge, UK.

Toth, F.L.,Bruckner, Th., Füssel, H.-M., Leimbach, M., Petschel-Held, G. and Schellnhuber, H.J. (1997). The tolerable windows approach to integrated assessments. Proceedings of the IPCC Asia-Pacific Workshop on Integrated Assessment Models, Tokyo, Japan, 10-12th March 1997. 